\title{
Immune Intervention for Type 1 Diabetes, 2013-2014
}

\author{
Jay S. Skyler
}

\section{Introduction}

T HIS ARTICLE OF THE YEARBOOK OF ADVANCED TECHNOLOGY AND TREATMENTS IN DIABETES reviews several clinical studies that have appeared between July 2013 and August 2014 in the area of immune intervention in type 1 diabetes (T1D).

The first article discussed is the first results from the Trial to Reduce IDDM in the Genetically at Risk (TRIGR), a much anticipated primary prevention trial.

\section{Hydrolyzed infant formula and early $\beta$-cell autoimmunity: a randomized clinical trial}

Knip $M^{1}$, Akerblom $H K^{1}$, Becker $D^{2}$, Dosch $H M^{3}$, Dupre $J^{4}$, Fraser $W^{5}$, Howard $N^{6}$, Ilonen $J^{7}$, Krischer $J P^{8}$, Kordonouri $O^{9}$, Lawson $M L^{10}$, Palmer $J P^{11}$, Savilahti $E^{1}$, Vaarala $\mathrm{O}^{12}$, Virtanen $\mathrm{SM}^{12}$; TRIGR Study Group

${ }^{1}$ University of Helsinki, Helsinki, Finland; ${ }^{2}$ University of Pittsburgh, Pittsburgh, PA; ${ }^{3}$ University of Toronto, Toronto, Ontario, Canada; ${ }^{4}$ University of Western Ontario, London, Canada; ${ }^{5}$ University of Montréal, Montréal, Québec, Canada; ${ }^{6}$ Children's Hospital of Westmead, Sydney, Australia; ${ }^{7}$ University of Turku, Turku, Finland; ${ }^{8}$ University of South Florida, Tampa; ${ }^{9}$ Kinder- und Jugendkrankenhaus AUF DER BULT, Hannover, Germany; ${ }^{10}$ Children's Hospital of Eastern Ontario, Ottawa, Ontario, Canada; ${ }^{11}$ University of Washington, Seattle, WA; and ${ }^{12}$ National Institute for Health and Welfare, Helsinki, Finland

JAMA 2014; 311: 2279-87

\section{Background}

Short duration of breast-feeding and/or early exposure to complex dietary proteins have been implicated as potential risk factors for $\beta$-cell autoimmunity and T1D. Extensively hydrolyzed formulas do not contain intact proteins. The Trial to test Reduce IDDM in the Genetically at Risk (TRIGR) Study was designed to test the hypothesis that weaning to an extensively hydrolyzed formula decreases the cumulative incidence of T1D in young children. Presentation of clinical T1D by age 10 years is the primary outcome of TRIGR, while positivity for 2 or more diabetes-associated autoantibodies by age 6 years is a secondary outcome, presented in this article.

\section{Methods}

The study randomized 2159 infants to receive either an extensively hydrolyzed casein formula or a conventional, cow's-milk based formula supplemented with $20 \%$ of the casein hydrolysate whenever breast milk was not available during the first 6-8 months of life. Eligible infants had HLAconferred susceptibility to T1D and at least one family member with T1D. Children were followed for a median observation period of 7.0 years (mean, 6.3 years). The outcome measure reported in this article was positivity for at least 2 diabetes-associated autoantibodies out of 4 analyzed (islet cell antibodies by immunofluorescence, and autoantibodies to insulin, glutamic acid decarboxylase, and the insulinoma-associated-2 [IA-2] molecule).

\section{Results}

In the group assigned to casein hydrolysate formula, $13.4 \%$ had 2 or more islet autoantibodies versus $11.4 \%$ among those randomized to the conventional formula (unadjusted hazard ratio 1.21 [95\% CI, 0.94-1.54]). When the hazard ratio was adjusted for HLA risk, duration of breastfeeding, vitamin D use, study formula duration and consumption, and region of the world, it was 1.23 [95\% CI, 0.96-1.58]. There was no difference in rate of adverse events.

\section{Conclusion}

Dietary intervention during infancy with a hydrolyzed formula, among infants at risk for T1D, did not reduce the incidence of diabetes-associated autoantibodies after 7 years.

\section{Comment}

Epidemiological studies have suggested that either short duration of breast-feeding and/or early exposure to cow's milk increases risk of T1D. The TRIGR Study Group reports on the appearance of diabetes autoantibodies and

Division of Endocrinology, Diabetes, \& Metabolism, and Diabetes Research Institute, University of Miami Miller School of Medicine, Miami, FL. 
has found that there is no difference in rate of appearance after 7 years. This is a very disappointing finding, particularly in that the pilot Finnish TRIGR Study Group found that the rate of appearance of diabetes autoantibodies was reduced in half (1). Yet, that pilot study included only 230 infants, compared to 2159 subjects in the TRIGR study. TRIGR has the development of T1D by age 10 as its primary outcome. Although the authors note that it still is possible that the hydrolyzed formula affects the degree and rate of progression to clinical $\mathrm{T} 1 \mathrm{D}$, to this writer that seems highly unlikely. This is yet another example of premature expectations raised by an underpowered pilot study (even though it included 230 infants), yet refuted by a full trial. As the authors state, the findings do not support a benefit from hydrolyzed formula. I would note, however, that in the epidemiological studies that suggested that early exposure to cow's milk increases risk, it was not possible to exclude that the risk was from short duration of breast-feeding. Since there are other benefits from breast-feeding, it should be encouraged for all women for as long as feasible in their given circumstances.

The next group of articles discusses randomized placebocontrolled clinical trials in recent-onset T1D.

\section{Targeting of memory $\mathrm{T}$ cells with alefacept in new-onset type 1 diabetes (T1DAL study): 12 month results of a randomized, double-blind, placebo-controlled phase 2 trial}

Rigby $M R^{1}$, DiMeglio $L A^{2}$, Rendell $M S^{3}$, Felner $E I^{4}$, Dostou $\mathrm{JM}^{5}$, Gitelman $\mathrm{SE}^{6}$, Patel $\mathrm{CM}^{7}$, Griffin $\mathrm{KJ}^{7}$, Tsalikian $E^{8}$, Gottlieb $P A^{9}$, Greenbaum $C^{10}$, Sherry $N A^{11}$, Moore $W V^{12}$, Monzavi $R^{13}$, Willi SM ${ }^{14}$, Raskin $P^{15}$, Moran $A^{16}$, Russell WE ${ }^{17}$, Pinckney $A^{18}$, Keyes-Elstein $L^{19}$, Howell $M^{19}$, Aggarwal $S^{19}$, Lim $N^{19}$, Phippard $D^{19}$, Nepom $G T^{10}$, McNamara $J^{20}$, Ehlers $M R^{21}$; T1DAL Study Team

${ }^{1}$ Indiana University and Riley Hospital for Children at Indiana University Health, Indianapolis, IN; ${ }^{2}$ Indiana University and Riley Hospital for Children at Indiana University Health, Indianapolis, IN; ${ }^{3}$ Creighton Diabetes Center, Omaha, NE; ${ }^{4}$ Emory University, Atlanta, GA; ${ }^{5}$ University of North Carolina, Durham, NC; ${ }^{6}$ University of California San Francisco, San Francisco, CA; ${ }^{7}$ University of Arizona, Tucson, AZ; ${ }^{8}$ University of Iowa, Iowa City, Iowa; ${ }^{9}$ Barbara Davis Center, University of Colorado, Aurora, CO; ${ }^{10}$ Benaroya Research Institute, Seattle, WA; ${ }^{11}$ Massachusetts General Hospital, Boston, MA; ${ }^{12}$ Children's Mercy Hospital, Kansas City, MO; ${ }^{13}$ Children's Hospital Los Angeles, Los Angeles, CA; ${ }^{14}$ Children's Hospital of Philadelphia, Philadelphia, PA; ${ }^{15}$ The University of Texas, Southwestern Medical Center, Dallas, TX; ${ }^{16}$ University of Minnesota, Minneapolis, MN; ${ }^{17}$ Vanderbilt University Medical Center, Nashville, TN; ${ }^{18}$ Rho Federal Systems Division, Chapel $\mathrm{Hill}, \mathrm{NC} ;{ }^{19}$ Immune Tolerance Network, Bethesda, $\mathrm{MD} ;{ }^{20} \mathrm{Na}$ tional Institutes of Allergy and Infectious Diseases, Bethesda, MD; and ${ }^{21}$ Immune Tolerance Network, San Francisco, CA

Lancet Diabetes Endocrinol 2013; 1: 284-94

\section{Background}

The immune targeting of the pancreatic $\beta$ cells is likely mediated, at least in part, by effector memory $\mathrm{T}$ (Tem) lymphocytes. CD2, a cell surface protein highly expressed on Tem cells, is targeted by the fusion protein alefacept, depleting Tem cells, and central memory $\mathrm{T}(\mathrm{Tcm})$ lymphocytes. The investigators postulated that alefacept would arrest autoimmunity and preserve residual $\beta$-cell function in recentonset T1D.

\section{Methods}

The study randomized 49 subjects, age $12-35$, who received alefacept (two 12-week courses of $15 \mathrm{mg}$ intramuscularly per week, separated by a 12-week pause) or placebo. The primary endpoint was change from baseline to 12 months in mean $2 \mathrm{~h}$ C-peptide area under the curve (AUC) during a mixed meal tolerance test (MMTT). Secondary endpoints were change from baseline to 12 months in the $4 \mathrm{~h} \mathrm{C}$-peptide AUC, insulin use, major hypoglycemic events, and HbAlc concentrations.

\section{Results}

The mean $2 \mathrm{~h}$ C-peptide AUC at 12 months increased by $0.015 \mathrm{nmol} / \mathrm{L}$ [95\% CI -0.080 to 0.110 ] in the alefacept group and decreased by $0.115 \mathrm{nmol} / \mathrm{L}$ in the placebo group, but the difference between groups was not significant $(p=0.065)$. On the other hand, mean $4 \mathrm{~h} \mathrm{C}$-peptide AUC was higher (mean increase of $0.015 \mathrm{nmol} / \mathrm{L}$ [95\% CI -0.076 to 0.106 ] in the alefacept group, versus a decrease of $-0.156 \mathrm{nmol} / \mathrm{L}$ in the placebo group, which was significant $[p=0.019]$. Daily insulin use was less with alefacept ( 0.36 units $/ \mathrm{kg} /$ day $)$ than with placebo $(0.48$ units $/ \mathrm{kg} / \mathrm{day})(p=0.02)$, and the rate of hypoglycemic events was less with alefacept (mean of 10.9 events/ person/year) than with placebo (17.3 events/person/year) $(p<0.0001)$. Mean HbA1c concentrations at 12 months were not different between treatment groups $(p=0.75)$. No serious adverse events were reported, and adverse event rates were similar between groups.

\section{Conclusion}

Although the primary outcome was not met, alefacept preserved the $4 \mathrm{~h}$ C-peptide AUC, lowered insulin use, and reduced hypoglycemic events. Safety and tolerability were similar in the alefacept and placebo groups.

\section{Comment}

This study creates an important conundrum. The nominal primary outcome measure $-2 \mathrm{~h}$ C-peptide AUC during an MMTT-was not met, while several secondary outcome measurers were positive in favor of alefacept, including $4 \mathrm{~h} \mathrm{C}$-peptide AUC, plus insulin dose and hypoglycemia rate. This demonstrates a potential issue, namely that with more data points being available over $4 \mathrm{~h}$ than $2 \mathrm{~h}$, the $4 \mathrm{~h} \mathrm{C}$-peptide AUC may be a more robust assessment of $\beta$-cell function. The $4 \mathrm{~h}$ test has not been routinely used at all time points because of the perception of "subject burden." Yet, if an indwelling catheter is in place for blood sampling, the difference is only $2 \mathrm{~h}$ 
of extra time. I think it would be desirable to make the standard duration of an MMTT $4 \mathrm{~h}$ rather than $2 \mathrm{~h}$. Another complicating feature of the study was that during enrollment the manufacturer withdrew alefacept from production and commercialization, thus forcing a reduction in sample size that was not anticipated. Had the study been fully enrolled, the nonsignificant $p$-value for $2 \mathrm{~h}$ C-peptide AUC ( $p=0.065)$ might have been significant. The study did achieve the expected changes in Tlymphocytes; that is, alefacept treatment resulted in significant increases in the Treg/CD4-Tcm and Treg/ CD4-Tem ratios. Thus, this reviewer would agree with the authors that "alefacept could be useful to preserve $\beta$-cell function in patients with recent-onset T1D."

\section{Combination therapy with sitagliptin and lanso- prazole in patients with recent-onset type 1 diabetes (REPAIR-T1D): 12-month results of a multicentre, randomized, placebo-controlled, phase 2 trial}

Griffin $K^{1}$, Thompson $P A^{1}$, Gottschalk $M^{2}$, Kyllo $\mathrm{JH}^{3}$, Rabinovitch $A^{l}$

${ }^{I}$ The Sanford Project, Sanford Research, and Sanford School of Medicine, University of South Dakota, Sioux Falls, SD; ${ }^{2}$ University of California San Diego and Rady Children's Hospital Pediatric Endocrinology, San Diego, CA; and ${ }^{3}$ Children's Hospitals and Clinics of Minnesota, St. Paul, MN

Lancet Diabetes Endocrinol 2014; 2: 710-18

\section{Background}

Preclinical studies have suggested that dipeptidyl peptidase-4 inhibitors and proton-pump inhibitors might enhance $\beta$-cell survival and regeneration. The investigators postulated that sitagliptin and lansoprazole would preserve $\beta$-cell function in patients with recent-onset T1D.

\section{Methods}

The study randomized 46 subjects, age $11-36$, who received oral sitagliptin (100 mg for participants $\geq 18$ years, $50 \mathrm{mg}$ for those $<18$ years) and lansoprazole $(60 \mathrm{mg}$ for participants $\geq 18$ years, $30 \mathrm{mg}$ for those $<18$ years) or matched placebo for 12 months. The primary endpoint was $2 \mathrm{~h} \mathrm{C}$ peptide AUC during an MMTT.

\section{Results}

At 12 months, the mean $2 \mathrm{~h}$ C-peptide AUC decreased by $0.229 \mathrm{nmol} / \mathrm{L}$ [ $95 \% \mathrm{CI}-0.316$ to -0.142$]$ in the experimental and by $0.253 \mathrm{nmol} / \mathrm{L}$ [ $95 \% \mathrm{CI}-0.383$ to -0.123 ) in the placebo group; this difference was not significant $(p=0.77)$. No adverse or serious adverse events were probably or definitely related to the study treatment.

\section{Conclusion}

Although the primary endpoint was not achieved, not all participants had increases in glucagon-like peptide-1 (GLP1) and gastrin concentrations that were expected with treatment. Thus, further studies may be warranted.

\section{Comment}

Using drugs that may enhance $\beta$-cell survival and regeneration is a good idea. In this study, using a combination that worked in experimental animals, there was not an effect on preserving $\beta$-cell function in human beings. The authors speculate that this may have been because the goal of achieving elevation of both GLP-1 and gastrin was not achieved in all subjects. This reviewer would argue that addressing $\beta$-cell survival and regeneration is one component of a needed intervention strategy, but that immune modulation must also be used if one is to be successful. The fact that the combination of sitagliptin and lansoprazole could be safely used elevates this combination to potential candidate status as two components of a multipronged approach to arresting the T1D disease process.

\section{Low-dose otelixizumab anti-CD3 monoclonal antibody DEFEND-1 Study: results of the randomized phase III study in recent-onset human type 1 diabetes}

Aronson $R^{1}$, Gottlieb $P A^{2}$, Christiansen $J S^{3}$, Donner $T W^{4}$, Bosi $E^{5}$, Bode $B W^{6}$, Pozzilli $P^{7,8}$; for the DEFEND Investigator Group

${ }^{1}$ LMC Diabetes \& Endocrinology, Toronto, Ontario, Canada; ${ }^{2}$ University of Colorado, Denver, CO; ${ }^{3}$ University of Aarhus, Aarhus University Hospital, Aarhus, Denmark; ${ }^{4}$ Johns Hopkins University School of Medicine, Baltimore, MD; ${ }^{5}$ San Raffaele Hospital Scientific Institute, Vita Salute San Raffaele University, Milan, Italy; ${ }^{6}$ Emory University, Atlanta Diabetes Associates, Atlanta, GA; ${ }^{7}$ Università Campus Bio-Medico di Roma, Rome, Italy; ${ }^{8}$ Barts and the London School of Medicine and Dentistry, Queen Mary, University of London, London, UK

Diabetes Care 2014; 37: 2746-54

\section{Efficacy and safety of low-dose otelixizumab anti-CD3 monoclonal antibody in preserving C-peptide secretion in adolescent type 1 diabetes: DEFEND-2, a randomized, placebo-controlled, double-blind, multi-center study}

Ambery $P^{1}$, Donner $T W^{2}$, Biswas $N^{l}$, Donaldson $J^{l}$, Parkin $\mathrm{J}^{1}$, Dayan $\mathrm{CM}^{3}$

${ }^{1}$ GlaxoSmithKline, Uxbridge, UK; ${ }^{2}$ Division of Endocrinology, Johns Hopkins University School of Medicine, Baltimore, MD; and ${ }^{3}$ Diabetes Research Group, Institute of Molecular and Experimental Medicine, Cardiff University School of Medicine, Cardiff, UK

\section{Diabetic Med 2014; 31: 399-402}

\section{Background}

Previous studies demonstrated that the anti-CD3 monoclonal antibody otelixizumab (administered at a total dose of 48-64 mg) can slow the loss of C-peptide in recent-onset T1D. The Durable Response Therapy Evaluation for Early or New-Onset Type 1 Diabetes (DEFEND) trials were designed to test whether a lower dose of otelixizumab could preserve C-peptide secretion in recent-onset T1D. 


\section{Methods}

Two phase III trials, DEFEND-1 and DEFEND-2, were conducted. They enrolled 281 and 179 subjects, respectively (the DEFEND-2 enrollment was halted after DEFEND-1 results became available). Subjects were of age 12-45. Treatment was either a total dose of $3.1 \mathrm{mg}$ otelixizumab (administered over 8 days) or placebo. The primary endpoint was change from baseline to 12 months in mean $2 \mathrm{~h} \mathrm{C}$-peptide area under the curve (AUC) during an MMTT.

\section{Results}

In DEFEND-1, the change in $2 \mathrm{~h}$ C-peptide AUC was not different between otelixizumab-treated subjects and placebotreated subjects $(-0.22$ vs. $-0.20 \mathrm{nmol} / \mathrm{L}, p=0.81)$. Also in DEFEND-2, the change in $2 \mathrm{~h}$ C-peptide AUC was not different between otelixizumab-treated subjects and placebo-treated subjects $(-0.23 \mathrm{vs} .-0.13 \mathrm{nmol} / \mathrm{L}, p=0.051)$. More patients in the otelixizumab group than in the placebo group experienced adverse events. However, there was no EBV reactivation.

\section{Conclusion}

Otelixizumab was well tolerated in patients with recentonset T1D at a total dose of $3.1 \mathrm{mg}$, but did not achieve preservation of levels of C-peptide or other markers of metabolic control.

\section{Comment}

The DEFEND trials illustrate a difficult issue in clinical trial design. In an earlier proof-of-concept randomized study (2), the anti-CD3 monoclonal antibody otelixizumab (administered at a total dose of $48 \mathrm{mg}$ ) slowed the loss of C-peptide in recent-onset T1D. Moreover, continuing evidence of effect was seen 4 years after the initial 6-day course of treatment (3). Yet, for the phase III DEFEND trials, the total dose was reduced to just $3.1 \mathrm{mg}$, a nearly 16 -fold reduction in dose. The dose reduction was an effort to eliminate side effects; as in the earlier study, severe symptoms of cytokine release syndrome (CRS) and reactivation of Epstein-Barr virus (EBV) were seen. In the DEFEND trials, true enough, symptoms of CRS were substantially milder, and there was no reactivation of EBV. Yet, to this reviewer, these side effects were not intolerable. CRS is transient, and the symptoms can be generally controlled with an analgesic and an anti-histamine. I, for one, would tolerate transient symptoms for a beneficial effect that has evidence of being sustained for 4 years, and the EBV reactivation that was seen was transient (4) and was predicted to occur and to be transient, and thus accepted by the Data Safety and Monitoring Committee (DSMB) of the earlier study of otelixizumab at the higher dose. I know this because I chaired that DSMB. Thus, in what I consider an unnecessary attempt to find a dose that eliminated side effects, the developer selected a dose that also eliminated beneficial effects. A sad tale for drug development, and an even sadder tale for T1D patients who might benefit from otelixizumab.

The following two manuscripts are discussed together.
Treatment of recent-onset type 1 diabetic patients with DiaPep277: results of a double-blind, placebo-controlled, randomized phase 3 trial

Raz $I^{1}$, Ziegler $A G^{2}$, Linn $T^{3}$, Schernthaner $G^{4}$, Bonnici $F^{5}$, Distiller $L A^{6}$, Giordano $C^{7}$, Giorgino $F^{8}$, de Vries $L^{9}$, Mauricio $D^{10}$, Procházka $V^{11}$, Wainstein $J^{12}$, Elias $D^{13}$, Avron $A^{13}$, Tamir $M^{13}$, Eren $R^{13}$, Peled $D^{13}$, Dagan $S^{13}$, Cohen IR ${ }^{14}$, Pozzilli $P^{15,16}$; DIA-AID 1 Writing Group

${ }^{1}$ Diabetes Unit, Department of Internal Medicine, Hadassah University Hospital, Jerusalem, Israel; ${ }^{2}$ Institute of Diabetes Research, Helmholtz Center, Klinikums Rechts der Isar, University of Technology, Munich, Germany; ${ }^{3}$ University Hospital, Giessen, Germany; ${ }^{4}$ Department of Medicine I, Rudolfstiftung Hospital, Vienna, Austria; ${ }^{5}$ UCT Private Academic Hospital, Cape Town, South Africa; ${ }^{6}$ Center of Diabetes Endocrinology, Johannesburg, South Africa; ${ }^{7}$ Department of Endocrinology, University of Palermo, Palermo, Italy; ${ }^{8}$ Department of Emergency and Organ Transplantation, Section of Internal Medicine, Endocrinology, Andrology, and Metabolic Diseases, University of Bari Aldo Moro, Bari, Italy; ${ }^{9}$ Institute for Endocrinology and Diabetes, Schneider Children's Medical Center, Petach Tikvah, Israel; ${ }^{10}$ Hospital Universitari Arnau de Vilanova, Lleida, Spain; ${ }^{11}$ Internal Clinic, Faculty Hospital, Olomouc, Czech Republic; ${ }^{12}$ Wolfson Medical Center, Holon, Israel; ${ }^{13}$ Andromeda Biotech Ltd., Yavne, Israel; ${ }^{14}$ Department of Immunology, Weizmann Institute of Science, Rehovot, Israel; ${ }^{15}$ Department of Endocrinology and Diabetes, University Campus Bio-Medico, Rome, Italy; and ${ }^{16}$ Center of Diabetes, Barts and the London School of Medicine, Queen Mary University of London, London, $U K$

Diabetes Care 2014; 37: 1392-400

\section{Evaluation of long-term treatment effect in a type 1 diabetes intervention trial: differences after stimulation with glucagon or a mixed meal}

Pozzilli $P^{1,2}$, Raz $I^{3}$, Peled $D^{4}$, Elias $D^{4}$, Avron $A^{4}$, Tamir $M^{4}$, Eren $R^{4}$, Dagan $S^{4}$, Cohen $I^{5}$

${ }^{1}$ Department of Endocrinology and Diabetes, University Campus Bio-Medico, Rome, Italy; ${ }^{2}$ Center of Diabetes, Barts and the London School of Medicine, Queen Mary University of London, London, UK, ${ }^{3}$ Diabetes Unit, Department of Internal Medicine, Hadassah University Hospital, Jerusalem, Israel; ${ }^{4}$ Andromeda Biotech Ltd., Yavne, Israel; and ${ }^{5}$ Department of Immunology, Weizmann Institute of Science, Rehovot, Israel

Diabetes Care 2014; 37: 1384-91

\section{Background}

Preclinical and earlier clinical studies have suggested that a 24 amino acid peptide derived from heat shock protein-60, named DiaPep277, had potential to preserve $\beta$-cell function in recent-onset T1D. This phase 3 study evaluated whether DiaPep277 would preserve $\beta$-cell function in adult patients with recent-onset T1D.

\section{Methods}

The study randomized 457 subjects, age 16-45, who received subcutaneous injections of DiaPep277 or placebo quarterly for 2 years. Two approaches were used to evaluate 
$\beta$-cell function, change from baseline AUC of C-peptide in response to a glucagon stimulation test (GST), and change from baseline in mean $2 \mathrm{~h}$ C-peptide AUC during an MMTT. Other secondary end points were fasting C-peptide and achieving target $\mathrm{HbA} 1 \mathrm{c} \leq 7 \%$. Partial remission (target HbA1c on insulin $\leq 0.5$ units/kg/day) and hypoglycemic event rate were exploratory end points.

\section{Results}

The results were complicated and difficult to interpret. There was a disparity between the two methods of evaluating C-peptide; namely, with the glucagon stimulation, a statistically significant preservation of C-peptide secretion was observed in the DiaPep277-treated group compared with the placebo, whereas the MMTT failed to distinguish between the groups. Significantly more DiaPep277-treated than placebo-treated patients maintained target $\mathrm{HbA} 1 \mathrm{c}$ and entered partial remission. DiaPep277 treatment also reduced the relative hypoglycemic event risk.

\section{Conclusion}

The authors concluded that DiaPep277 is safe and may contribute to preservation of $\beta$-cell function and to improved glycemic control in T1D.

\section{Comment}

The conflicting results from the two measures of C-peptide create difficulty in interpretation. Depending on which measure one accepts, this was either a positive trial (based on GST) or a negative trial (based on MMTT). A complicating feature is that the primary outcome measure was changed from the MMTT to the GST during the trial. Indeed, the authors state that "the study protocol was amended, and the statistical analysis plan was planned and finalized before the study was unblinded, with the GST clearly defined as the primary end point." Since MMTT was the original primary outcome measure, it was performed at randomization (month 0 ) and after $6,12,18$, and 24 months - a total of five measurements. Since GST originally was a secondary outcome measure, it was performed at month 1 (defined as "baseline" for the GST, but 1 month after the first treatment had been given) and at 12 and 24 months - a total of three measurements. Thus, the MMTT was more robustly assessed. Given the differences in outcomes between tests, it would seem desirable to further compare the MMTT and the GST within future trials of interventions in T1D. In the meantime, we are stuck with an unclear result from this study.

The next group of articles discuss nonrandomized clinical trials in recent-onset T1D, either without control subjects or with a nonrandomized comparison group.

\section{Therapy of type 1 diabetes with CD4(+) CD25(high)CD127-regulatory $T$ cells prolongs survival of pancreatic islets-results of one year follow-up}

Marek-Trzonkowska $N^{1}$, Myśliwiec $M^{2}$, Dobyszuk $A^{3}$, Grabowska $M^{3}$, Derkowska $I^{2}$, Juścińska $J^{4}$, Owczuk $R^{5}$,
Szadkowska $A^{6}$, Witkowski $P^{7}$, M1ynarski $W^{6}$, JaroszChobot $P^{8}$, Bossowski $A^{9}$, Siebert $J^{1}$, Trzonkowski $P^{3}$

${ }^{1}$ Department of Family Medicine, Medical University of Gdańsk, Gdańsk, Poland; ${ }^{2}$ Department of Pediatric Diabetology and Endocrinology, Medical University of Gdańsk, Gdańsk, Poland; ${ }^{3}$ Department of Clinical Immunology and Transplantology, Medical University of Gdańsk, Gdańsk, Poland; ${ }^{4}$ Regional Center of Blood Donation and Treatment, Hoene-Wronskiego, Gdańsk, Poland; ${ }^{5}$ Department of Anesthesiology and Critical Care, Medical University of Gdańsk, Gdańsk, Poland; ${ }^{6}$ Department of Pediatrics, Oncology, Hematology and Diabetology, Medical University of Łódź, Łódź, Poland; ${ }^{7}$ Department of Surgery, Section of Transplantation, The University of Chicago, Chicago, IL; ${ }^{8}$ Department of Pediatrics, Endocrinology and Diabetes, Medical University of Silesia, Katowice, Poland; and ${ }^{9} \mathrm{De}-$ partment of Pediatrics Endocrinology and Diabetology, Medical University of Biatystok, Biatystok, Poland

Clin Immunol 2014; 153: 23-30

\section{Background}

Two years ago these authors described the safety of infusion of CD4(+)CD25(+)FoxP3(+) regulatory T-lymphocytes (Tregs) in T1D. The current report extends these observations to 1 year, and includes efficacy results.

\section{Methods}

A cohort of 12 children with recent-onset T1D was treated with ex vivo-expanded autologous Tregs, at 3 different doses in a dose-escalation study. Six of the treated children received a second infusion of Tregs after a 6-9-month interval. General health and metabolic status of treated individuals was evaluated at 4 and 12 months and compared to 10 nontreated control subjects matched for age, gender, and disease duration. The primary endpoints of the trial were safety and "remission" defined as insulin dose $\leq 0.5$ units $/ \mathrm{kg} /$ day together with fasting C-peptide $>0.5 \mathrm{ng} / \mathrm{mL} 1$ year after recruitment. C-peptide was also evaluated by GST at 1 year.

\section{Results}

Most of the patients responded to the therapy with increase in C-peptide levels (8/12 and 4/6 after the first and the second dose, respectively). Tregs administration resulted also in lower requirement for exogenous insulin $(8 / 12$ treated patients versus $2 / 10$ untreated controls in remission) with two children completely insulin independent at 1 year.

\section{Conclusion}

Repetitive administration of Tregs is safe and can prolong survival of $\beta$-cells in T1D.

\section{Comment}

This report extends the observations by this group on autologous Treg therapy in T1D. The findings suggest that Tregs may prove to have therapeutic efficacy, without major adverse events. Other studies with Tregs are underway. As noted in my comment 2 years ago on 
the initial report from this group, a question remains whether even better results might be achieved had the study used antigen-specific Tregs rather than polyclonal Tregs. There clearly needs to be careful investigation of both polyclonal and antigen-specific Tregs, as efforts are made to develop a therapeutic strategy to induce immune tolerance and stabilize T1D.

\section{Autologous nonmyeloablative hematopoietic stem cell transplantation in new-onset type 1 diabetes: a multicenter analysis}

D'Addio $F^{1,2}$, Valderrama Vasquez $A^{2}$ Ben Nasr $M^{1}$, Franek $E^{3,4}$, Zhu $D^{5}$, Li $L^{5}$, Ning $G^{6}$, Snarski $E^{7}$, Fiorina $P^{1,2}$

${ }^{1}$ Nephrology Division, Boston Children's Hospital, Harvard Medical School, Boston, MA; ${ }^{2}$ Transplant Medicine, IRCCS San Raffaele Hospital, Milan, Italy; ${ }^{3}$ Department of Internal Diseases, Diabetology and Endocrinology, Central Hospital, Ministry of Interior Affairs and Administration, Warsaw, Poland; ${ }^{4}$ Department of Endocrinology, Mossakowski Medical Research Centre, Polish Academy of Sciences, Warsaw, Poland; ${ }^{5}$ Division of Endocrinology, The Affiliated Drum Tower Hospital of Nanjing University, Nanjing, Jiangsu, People's Republic of China; ${ }^{6}$ Shangai Jiao Tong University School of Medicine, Shanghai, People's Republic of China; and ${ }^{7}$ Department of Hematology, Oncology and Internal Diseases, Medical University of Warsaw, Warsaw, Poland

Diabetes 2014; 63: 3041-46

\section{Background}

Previously, a Brazilian study described beneficial effects of autologous nonmyeloablative hematopoietic stem cell transplantation (AHSCT) in patients with recent-onset T1D. The current study pools data from three centers evaluating the effects of AHSCT.

\section{Methods}

The study enrolled 65 subjects, age 12-35, with recentonset T1D, who received conditioning immunosuppression therapy (with antithymocyte globulin and cyclophosphamide) and a single infusion of AHSCT. They were followed for 48 months.

\section{Results}

A total of $59 \%$ of individuals with T1D achieved insulin independence within the first 6 months, and 32\% remained insulin independent at the last time point of their follow-up. All treated subjects showed a decrease in HbA1c levels and an increase in C-peptide levels compared with pretreatment. $52 \%$ of subjects experienced adverse effects, including 1 death.

\section{Conclusion}

The authors conclude that remission of T1D is possible by combining AHSCT and immunosuppression, that this strat- egy may represent an effective treatment for selected individuals with T1D, but that safer AHSCT-based therapeutic options are required.

\section{Comment}

This study is quite provocative, because like the earlier Brazilian study, insulin independence was achieved in a substantial portion of study subjects. Yet, again, without a randomized controlled clinical trial, one cannot be certain of the effects of the intervention. Moreover, the death of one subject ( $1.5 \%$ death rate, akin to the $1-3 \%$ death rate often seen with AHSCT) raises ethical concerns. Moreover, it is impossible to ascertain whether the apparent effects are due to AHSCT per se, or rather to the profound conditioning immunosuppression therapy (antithymocyte globulin and cyclophosphamide), in which case the AHSCT serves to rescue the patient from death from aplastic anemia and destruction of their immune system. Thus, this reviewer agrees with the authors that safer AHSCT-based therapeutic options are required.

\section{Low-dose interleukin 2 in patients with type 1 diabetes: a phase $1 / 2$ randomized, double-blind, placebo-controlled trial}

Hartemann $A^{1}$, Bensimon $G^{2,6}$, Payan $C A^{2}$, Jacqueminet $\mathrm{S}^{1}$, Bourron $\mathrm{O}^{1}$, Nicolas $\mathrm{N}^{3}$, Fonfrede $\mathrm{M}^{4}$, Rosenzwajg $M^{5,7-9}$, Bernard $C^{5,7-9}$, Klatzmann $D^{5,7-9}$

${ }^{1}$ Department of Diabetology, ${ }^{2}$ Department of Clinical Pharmacology, ${ }^{3}$ Clinical Investigation Center ParisEst-CIC-9304, ${ }^{4}$ Department of Biochemistry, and ${ }^{5}$ Clinical Investigation Center for Biotherapies and InflammationImmunopathology-Biotherapy Department AP-HP, Hôpital Pitié-Salpêtrière, Paris, France; ${ }^{6}$ Pharmacologie, Paris, France; ${ }^{7}$ Immunology-Immunopathology-Immunotherapy UPMC Univ Paris 06, Paris, France; ${ }^{8}$ INSERM, UMR_S 959, Immunology-Immunopathology-Immunotherapy, Paris, France; and ${ }^{9} \mathrm{CNRS}$, UMR 7211, ImmunologyImmunopathology-Immunotherapy, Paris, France

Lancet Diabetes Endocrinol 2013; 1: 295-305

\section{Background}

Low-dose interleukin 2 (IL-2) has been shown to induce Treg cell expansion and activation, along with clinical improvement in several disease settings. The investigators sought to determine which low doses of IL-2 would be safe and induce Treg cells in patients with T1D.

\section{Methods}

The study randomized 24 subjects, age 18-55, with established T1D and at least one diabetes-related autoantibody. Subjects were randomly assigned (in a 1:1:1:1 ratio) to placebo or IL-2 at $0.33 \mathrm{MIU} /$ day, $1 \mathrm{MIU} /$ day, or $3 \mathrm{MIU} /$ day for a 5 -day course and then followed for 60 days. The primary outcome was change in Treg cells, measured by flow cytometry, and expressed as a percentage of CD4 $+\mathrm{T}$ cells, from day 1 to day 60 . 


\section{Results}

IL-2 was well tolerated at all doses, with no serious adverse events. However, there was a dose-dependent association of nonserious adverse events during the treatment phase. The most common adverse events were injection-site reaction and influenza-like syndrome. After the treatment phase, adverse events did not differ between groups. IL-2 induced a dosedependent increase in the proportion of Treg cells, significant at all doses compared with placebo. IL-2 did not induce deleterious changes in glucose-metabolism variables.

\section{Conclusion}

IL-2 was well-tolerated and immunologically effective, which could be relevant to both T1D and other disorders in which a Treg cell increase would be desirable.

\section{Comment}

IL-2 is an important factor in T-lymphocyte expansion. Low doses of IL- 2 have been shown to increase Treg cells and improve clinical outcome in hepatitis-C-virusinduced vasculitis and in graft-versus-host disease. However, higher doses of IL-2 can also expand Teffector cells, eosinophils, and NK cells. When studied in a pilot study in T1D, high-dose IL-2 used together with rapamycin led to a reduction in $\beta$-cell function (5). This has caused some to shy away from considering IL-2 as an agent for intervention in T1D. Yet, the current study shows the fallacy of doing such. In this phase $1 / 2$ study, IL-2 was well-tolerated, resulted in expansion of Tregs, and did not appear to induce deleterious effects on $\beta$-cell function. As a consequence, low-dose IL- 2 is moving forward in adequately powered, randomized, controlled clinical trials in T1D. We eagerly await the results.

\section{$\alpha 1$-Antitrypsin therapy downregulates toll-like receptor-induced IL-1 $\beta$ responses in monocytes and myeloid dendritic cells and may improve islet function in recently diagnosed patients with type 1 diabetes}

Gottlieb $P A^{1}$, Alkanani $A K^{1}$, Michels $A W^{1}$, Lewis $E C^{2}$, Shapiro $L^{3}$, Dinarello $C A^{4}$, Zipris $D^{1}$

${ }^{1}$ Barbara Davis Center for Childhood Diabetes, University of Colorado Denver, Aurora, CO; ${ }^{2}$ Department of Clinical Biochemistry and Pharmacology, Faculty of Health Sciences, Ben-Gurion University of the Negev, Beer-Sheva, Israel; ${ }^{3}$ Division of Infectious Diseases, Department of Medicine, Veterans Affairs Medical Center and University of Colorado Denver, Denver, CO; and ${ }^{4}$ Division of Infectious Diseases, University of Colorado Denver, Aurora, Colorado

J Clin Endocrinol Metab 2014; 99: E1418-26

\section{Background}

Proinflammatory responses have been implicated in the development of T1D. $\alpha 1$-Antitrypsin (AAT) is an antiinflammatory serum protein. This phase 1 study evaluated the safety and effects of AAT therapy in T1D.

\section{Methods}

The study evaluated 12 subjects, age 12-39, diagnosed with T1D within 4 years and with detectable C-peptide, who received weekly infusions of AAT for 8 consecutive weeks. Subjects were monitored for adverse effects of AAT therapy, C-peptide responses to a mixed-meal tolerance test, and tolllike receptor (TLR)-induced cellular IL-1 $\beta$ in monocytes and myeloid dendritic cells (mDCs).

\section{Results}

No adverse effects were detected. In five subjects, there were increased, unchanged, or moderately reduced levels of C-peptide responses. IL-1 $\beta$ was reduced by AAT in monocytes and mDCs. Improved $\beta$-cell function in the five AATtreated individuals correlated with lower frequencies of monocytes and $\mathrm{mDCs}$ producing IL- $1 \beta$.

\section{Conclusion}

The authors assert that AAT may have a beneficial effect on T1D that is associated with downmodulation of IL-1 $\beta$.

\section{Comment}

This is a small pilot study. AAT was shown to be safe in T1D. There were hints of potential efficacy, particularly in terms of reduction in cellular IL- $1 \beta$. Moreover, this appeared to be correlated with retained $\beta$-cell function. The problem is that such retained $\beta$-cell function was only seen in 5 of 12 subjects. The lack of a control group makes that finding impossible to interpret. Yet, given the safety, a full randomized, placebo-controlled trial appears warranted.

\section{Overall Commentary}

This year I have reviewed 11 articles relating to 10 studies, 1 aimed at primary prevention, and the others studied in relatively recent-onset T1D. Sadly, none of the studies have been unambiguously positive. Yes, the alefacept study and the DiaPep277 study reported positive results, but each with a caveat. The AHSCT study reported a high frequency of insulin independence, but with a mortality risk and absent a control group. Thus, negative studies continue to dominate the field. My bias is that combination approaches are needed. And these combinations should address both the $\beta$-cell per se (as was done in the REPAIRT1D study using sitagliptin and lansoprazole) and the immune system. Concerning the latter, it may be necessary to consider both the innate immune system and the adaptive immune system. Hopefully, regulatory agencies will be flexible in their approval of trials with multiple agents. There certainly are many different combinations that can be studied. Such efforts need to get underway.

\section{Author Disclosure Statement}

J.S.S. is chairman of Type 1 Diabetes TrialNet, which is studying a variety of interventions for T1D. There are no other potential conflicts of interest relevant to this article. 


\section{References}

1. Knip M, Virtanen SM, Seppä K, Ilonen J, Savilahti E, Vaarala O, Reunanen A, Teramo K, Hämäläinen AM, Paronen J, Dosch HM, Hakulinen T, Akerblom HK. Finnish TRIGR Study Group. Dietary intervention in infancy and later signs of beta-cell autoimmunity. New Engl J Med 2010; 363: 1900-1908.

2. Keymeulen B, Vandemeulebroucke E, Ziegler AG, Mathieu C, Kaufman L, Hale G, Gorus F, Goldman M, Walter M, Candon S, Schandene L, Crenier L, De Block C, Seigneurin JM, De Pauw P, Pierard D, Weets I, Rebello P, Bird P, Berrie E, Frewin M, Waldmann H, Bach JF, Pipeleers D, Chatenoud L. Insulin needs after CD3-antibody therapy in new-onset type 1 diabetes. New Engl J Med 2005; 352: 2598-608.

3. Keymeulen B, Walter M, Mathieu C, Kaufman L, Gorus F, Hilbrands R, Vandemeulebroucke E, Van de Velde U, Crenier L, De Block C, Candon S, Waldmann H, Ziegler AG, Chatenoud L, Pipeleers D. Four-year metabolic out- come of a randomised controlled CD3-antibody trial in recent-onset type 1 diabetic patients depends on their age and baseline residual beta cell mass. Diabetologia 2010; 53: 614-623.

4. Keymeulen B, Candon S, Fafi-Kremer S, Ziegler A, LeruezVille M, Mathieu C, Vandemeulebroucke E, Walter M, Crenier L, Thervet E, Legendre C, Pierard D, Hale G, Waldmann H, Bach JF, Seigneurin JM, Pipeleers D, Chatenoud L. Transient Epstein-Barr virus reactivation in CD3 monoclonal antibody-treated patients. Blood 2010; 115: 1145-1155.

5. Long SA, Rieck M, Sanda S, Bollyky JB, Samuels PL, Goland R, Ahmann A, Rabinovitch A, Aggarwal S, Phippard D, Turka LA, Ehlers MR, Bianchine PJ, Boyle KD, Adah SA, Bluestone JA, Buckner JH, Greenbaum CJ. Diabetes TrialNet and the Immune Tolerance Network. Rapamycin/IL-2 combination therapy in patients with type 1 diabetes augments Tregs yet transiently impairs $\beta$-cell function. Diabetes 2012; 61: 2340-48. 